\title{
Digital humanities: als een fraai essay
}

\author{
Essayprijs Huizinga Instituut 2016 \\ Leonor Álvarez Francés \\ TVGESCH 130 (2): 249-256 \\ DOI: 10.5117/TVGESCH2017.2.FRAN
}

\begin{abstract}
The digital humanities: like a witty essay

While digital approaches to research in the humanities have greatly increased in the last decades, many scholars rightly criticize the lack of knowledge their peers have of the methods and tools they are applying. Most importantly, there is a concern as to how the digital dimension is affecting the humanities as a field in general. In this essay I argue that, when used responsibly, digital methods and tools are hugely attractive for widening the scope of our research topics, for collaboration, and for sharing our knowledge with a broader public. These possibilities can have long-term repercussions in workflow practices, but do not imply the undermining of the fundaments of the humanities as a study area. The digital humanities work like a witty essay: they stimulate critical thinking, expand our horizons, and open up fundamental debates.
\end{abstract}

Keywords: digital humanities, data integration, public history

Toen ik acht jaar oud was, kregen we thuis Encarta. De digitale encyclopedie bood een nieuwe wereld om te ontdekken. Ik herinner me nog dat ik vaak talen zat te leren. Natuurlijk kon dat ook met de dikke woordenboeken uit de boekenkast. Maar met Encarta kon ik luisteren naar de uitspraak van het Franse gezegde 'C'est la vie', doorklikken naar de gelijknamige film uit 1991 en leren dat Edwin Land, de uitvinder van de Polaroid, in datzelfde jaar overleden was. Op deze manier legde ik nieuwe verbanden en stuitte ik vaker op onverwachte kennis. Mijn fascinatie was eindeloos omdat Encarta zelf óók eindeloos leek te zijn.

Twintig jaar later heeft de relatie tussen computers en onze kwalitatieve belangstelling niets aan relevantie ingeboet. Integendeel, het brede veld van de digital humanities biedt aan bibliothecarissen de kans om historisch materiaal digitaal beschikbaar te maken en te indexeren. Onderzoekers zien digital humanities als een 


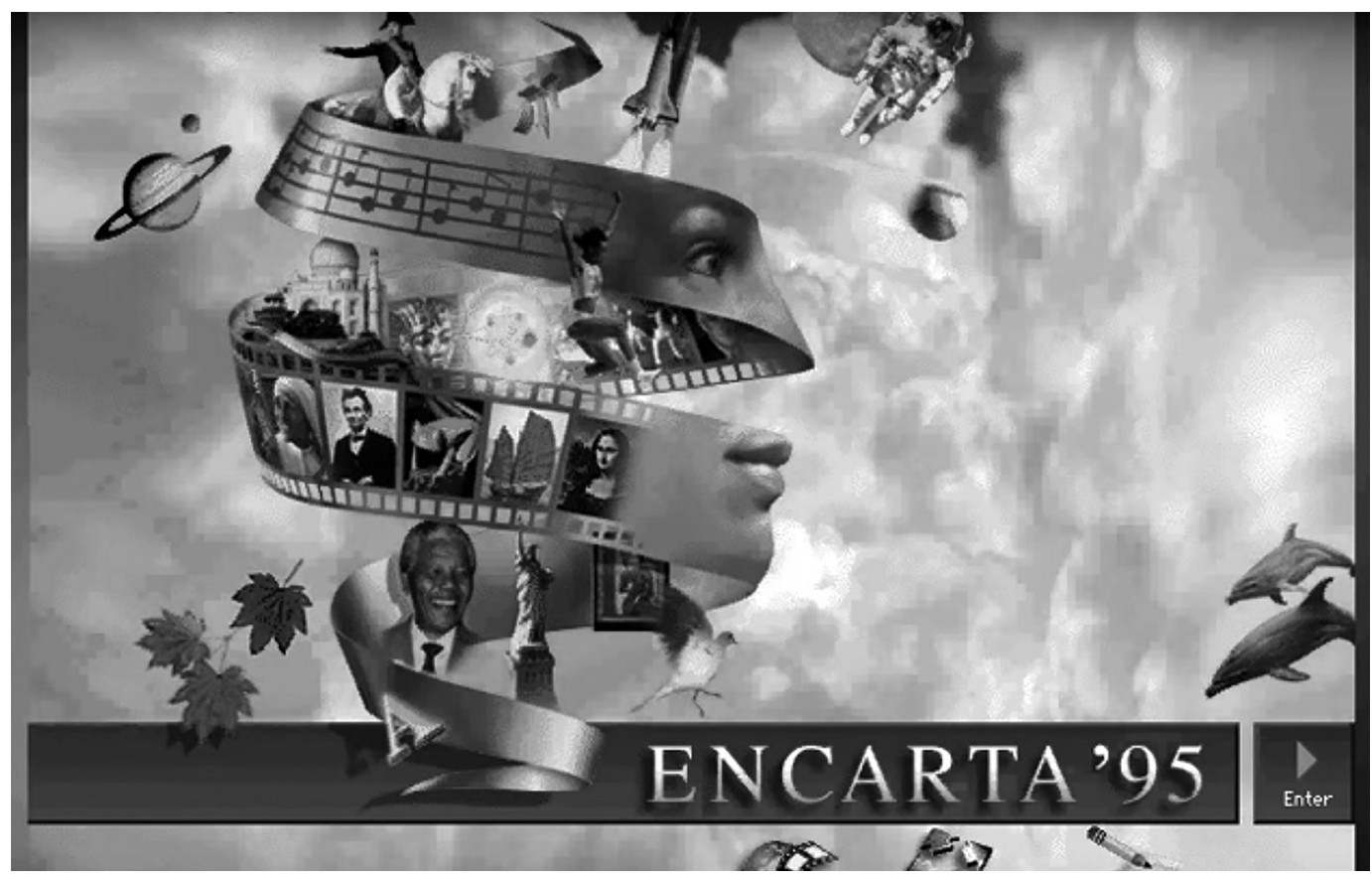

Het openingsscherm van Encarta '95

Screenshot Youtube.com

manier om bergen aan data bij elkaar te brengen in digitale databases, maar ook als uitgelezen technologie voor het uitpluizen van patronen die bovendien gepresenteerd kunnen worden in keurige en kleurige visualisaties. Honderden studies zijn er inmiddels aan gewijd en congressen brengen de liefhebbers uit de alfaen bètahoeken regelmatig samen.

Toch is niet iedereen even enthousiast over deze ontwikkelingen en klinken er tegengeluiden. Het lijkt vanzelfsprekend dat cultuurwetenschappers zelfverzekerd genoeg in hun vakbeoefening zijn om te weten dat geen enkele volkomen kwantitatieve aanpak het kwalitatieve onderzoek aan de kant kan schuiven. En toch heerst de vrees dat computationeel onderzoek de meer traditionele vormen van bronnenonderzoek onder druk zet.

Waar komt die angst vandaan? Het zijn zeker geen paranoïde gedachten; zo las ik laatst in de aankondiging van een lezing van de grand old man van de Middelnederlandse letterkunde, Frits van Oostrom, in Leiden: 'Als je niet online bent, ben je dood. De neerlandistiek moet zo snel mogelijk een digitale inhaalslag maken, wil zij nog relevant blijven voor toekomstige generaties.'

Ikzelf word onrustig en ongemakkelijk als ik naar de zoveelste presentatie luister die verkondigt dat de digitale dimensie het begin van een gloednieuw en onvermijdelijk tijdperk voor de humaniora is. Alsof het de Steen der Wijzen is die ons vak niet alleen radicaal anders maakt, maar ook 'inherent beter'. Natuurlijk sta

1 Persbericht Universiteit Leiden, 30 augustus 2016, https://www.universiteitleiden.nl/nieuws/2016/08/ frits-van-oostrom- $\% \mathrm{E}_{2} \% 80 \% 98$ als-je-niet-onlinebent-ben-je-dood\%E2\%80\%99 (geraadpleegd 3 februari 2017). 
ik open voor nieuwe trends, maar wil dat zeggen dat de onderzoekers die ik bewonder om hun analytisch vermogen, om hun literaire stijl, om hun capaciteit bronnen te vinden en te doorgronden, minderwaardig bezig zijn omdat ze geen verstand hebben van het programmeren van algoritmes? Deze onrust kan dus te maken hebben met de vrees dat we zonder al die nieuwe, onbekende kennis niet meer kunnen excelleren binnen ons vakgebied.

Niet alleen het idee van minderwaardigheid kan de geesten op hol doen slaan. Degenen onder ons die vertrouwd zijn met de digital humanities zitten immers ook te fronsen op congressen. Kritiek komt tevens voort uit de resultaten van digitaal-gebaseerd onderzoek. Zo vroeg ik eens na zo'n triomfantelijke presentatie: 'Hoe is dit radicaal anders dan nietdigitaal onderzoek? Hadden we dit niet ook met traditionele methodes kunnen doen?' De reactie sprak - in goed Nederlands - boekdelen: de spreker stond wat te schutteren en de horror vacui leidde tot een zinloos, meanderend verhaal om maar te ontsnappen aan de pijnlijke stilte. Zo'n situatie veroorzaakt irritatie en teleurstelling doordat de zogenaamde digitale paradigm shift in de praktijk tekortschiet. Jacob Grimm had per slot van rekening geen laptop nodig om taalkundige patronen en stambomen te ontdekken en ze van precieze voorbeelden te voorzien!

Maar stel dat de sprekers wel op verantwoorde wijze over methodologie hebben nagedacht, dan kun je genuanceerdere antwoorden te horen krijgen in de trant van: 'Het is veel sneller dan wanneer je het handmatig doet' of 'Het bevestigt met cijfers en patronen onomstotelijk dat onze voorlopers (on)gelijk hadden'. Deze antwoorden zijn interessant, want ze onthullen twee belangrijke aspecten waar cultuurwetenschappers onrustig van worden: hun beperkte onderzoekstijd, en de louter kwalitatieve - dus potentieel bestrijdbare - onderzoeksresultaten.

Het eerste aspect is kenmerkend voor onze tijdgeest. We hebben altijd haast en nergens meer tijd voor. Denk aan de services die tegenwoordig verleend worden: voor een extra bedrag sla je de wachtrij op Schiphol over, worden de boodschappen thuis gebracht of mag je met de Intercity Direct reizen. Allemaal prima, als het je leven makkelijker maakt. Voor de onderzoekspraktijk heeft haast echter grotere implicaties dan simpelweg ergens eerder aankomen of niet het huis te hoeven verlaten. Is sneller per se beter voor het beantwoorden van jouw onderzoeksvraag? En wat lever je in ruil voor die tijdswinst precies in? Met het gebruik van bijvoorbeeld een digitale database verandert de methodologie, wat fundamentele gevolgen kan hebben voor het onderzoek als geheel. En dan heb ik het nog niet over de enorme hoeveelheid tijd die het bedenken en opbouwen van digitale werkplannen en gereedschap in beslag kan nemen. Snelheid is dus ook geen vanzelfsprekendheid bij digitaal onderzoek.

Het aspect van de controleerbaarheid van de onderzoeksresultaten ligt gevoeliger omdat onduidelijke kwesties en onvolledige gegevens inherent zijn aan de cultuurwetenschappen. De vraag die de opkomst van digital humanities oproept is: hoe gaan we om met het ongrijpbare karakter van onze onderwerpen en resultaten? Nadat ik een digitale toneeldatabase had gemaakt en aan een collega had getoond, riep hij uit: 'We wisten het al, maar 
nu? Nú kunnen we het bewíjzen!' En hij had gelijk. Het betrof het feit dat de grootste dichter van de Spaanse Gouden Eeuw, Lope de Vega, meer opvoeringen genoot op het toneel van de Amsterdamse Schouwburg dan de grootste dichter van de Nederlandse Gouden Eeuw, Joost van den Vondel. Een boude bewering die ons vertrouwde beeld van het verleden nogal aan het wankelen brengt, en voor de overtuiging best wel wat cijfers en grafieken kan gebruiken.

Nu moet ik eerlijk bekennen dat deze ontdekking in eerste instantie handmatig plaatsvond, dankzij een op papier uitgegeven 'telefoonboek' van opvoeringsgegevens. Toentertijd zou ik echter heel erg blij zijn geweest met de digitale versie van deze database, omdat het onderzoek dan inderdaad sneller was gegaan en omdat ik harde cijfers en grafieken wilde hebben ter ondersteuning. De digitalisering was dus praktisch gezien heel wenselijk geweest; maar inhoudelijk niet per se onontbeerlijk. Mijn onderzoeksvraag en mijn resultaten kunnen sneller, duidelijker en overtuigender gepresenteerd worden met behulp van digitaal gereedschap, maar ze zijn er niet inherent door veranderd.

Waarom ben ik dan toch nog altijd gefascineerd door een genuanceerde interactieve kaart of een goed gebouwde netwerkvisualisatie? Ik vermoed dat dat te maken heeft met de schijn van perfectie van zulke voorstellingen, met diezelfde glans van alomvattendheid die de Encarta-encyclopedie ook uitstraalde. Het is voor onderzoekers van het verleden ondenkbaar dat we ooit alles te weten komen over onze onderwerpen, en dus ook om perfect afgebakende gegevens te produceren. Hoe kunnen zulke databanken en vlekkeloze visualisaties dan gemaakt worden? Hoe construeer je een digitale structuur, die gemaakt is voor exacte data, met gegevens als 'William Shakespeare werd geboren circa 26 april 1564 in de Juliaanse kalender'?

Aan deze kwestie ligt een nog belangrijkere vraag ten grondslag: waarom zou het überhaupt de moeite waard zijn om hier een computationele oplossing voor te vinden? Het proces kost veel tijd, geld en kennis van computerexperts, terwijl het weinig resultaat belooft voor een cultuurwetenschapper die vooral op zeldzame details gericht is. Een digitale aanpak is dus niet per se nuttig voor iedere onderzoeksvraag. Des te meer omdat het onverantwoordelijk zou zijn om als wetenschapper digitaal gereedschap te gebruiken waarbij je geen benul hebt van wat het precies bevraagt en zegt. Voor je het weet sta je net als de spreker van hierboven te happen naar lucht: 'Hoe dit specifieke programma de opstelling van mijn netwerkvisualisatie beïnvloed heeft en wat dat betekent voor mijn resultaten, vraag je? Nou eh...' Kortom: wil je je richten op afzonderlijke thema's zoals de decoratie van rituele objecten van een verloren gemeenschap in de Amazone? En heb je daarbij geen zin om na te denken wat een eventuele computationele dimensie verandert aan jouw onderzoek? Fair enough, maar blijf dan vooral ver van de digital humanities.

Toch, zodra het idee om achterliggende patronen te ontdekken je prikkelt, is het zinnig om eens een kijkje te nemen in de instrumentenverzameling van de digital humanities. Alleen, wat doe je dan met ambivalente complicaties zoals de geboortedatum van Shakespeare? Het zijn 
juist dit soort obstakels die de schoonheid van databases voor de humaniora openbaren. Het proces van het maken van een digitale database confronteert ons namelijk met de aard van onze specifieke kennis en gegevens. Welke data krijgen aandacht? Welke verbindingen staan daarbij voorop? Waar liggen de conflicten precies? En uiteindelijk: wat zegt dit allemaal over de uitgangspunten en denkprocessen van de geesteswetenschapper?

Computerwetenschappers denken namelijk heel anders over data dan geesteswetenschappers, omdat ze een andere focus hebben. Het zijn 'big data'-mensen: ze werken met enorme hoeveelheden gegevens waarvan de geboortedatum van Shakespeare slechts één extra rij in een gigantische dataset is. Ze interesseren zich voor algemene trends en voor de verbanden daartussen. Net als velen onder ons trouwens. In dit streven naar het ontdekken van patronen komen alfa en bèta samen, al is het vanuit zeer uiteenlopende invalshoeken.

We kunnen er dus over mopperen dat computerwetenschappers - en daarmee hun programma's - niet meteen begrijpen dat de nuances en onzekerheden rondom Shakespeare juist enorm belangrijk zijn. Maar we kunnen er ook mee werken. De digital humanities zorgen voor een leerproces van vallen en opstaan, waarbij ze de kans bieden om te reflecteren op en te leren over de gegevens waarmee we werken: waarom en wanneer zijn de onzekerheden rondom onze gegevens van belang? De voordelen van de computationele werkwijze kunnen daarbij een drijvende kracht zijn. Een papieren kaartendatabase met lemma's, jaartallen en afbeeldingen kent een vaste structuur en is alleen voor een klein publiek toegankelijk. Een digita- le database is daarentegen oneindig, niet alleen omdat deze voor iedereen met toegang tot het internet raadpleegbaar is, maar ook omdat één dataset gekoppeld kan worden aan andere datasets. De schat aan gegevens die één gespecialiseerde onderzoeker heeft opgebouwd kan een encyclopedie worden wanneer die is samengevoegd met andere collecties.

Ik zie data-integratie dan ook als de grote kracht en de toekomst van de digital humanities. Verzamelingen wijken meestal qua vorm van elkaar af, maar een digitale database kan omgevormd en opnieuw gestructureerd worden en is daarmee veel flexibeler dan een statische kaartenbak. Het integreren van uiteenlopende datasets is ook interessant vanuit inhoudelijk oogpunt. Bijvoorbeeld wanneer het leidt tot onverwachte vondsten, tot uitvindingen zoals die zich ook in het archief of op Encarta voordoen, tot de magie van serendipiteit. Daarenboven wint het oorspronkelijke onderzoeksthema aan omvang en komen nieuwe verbanden met andere periodes, tradities en plaatsen naar voren.

Een voorbeeld is de casus van de Bentvueghels, de schilders uit de Lage Landen die in Rome hebben gewoond tijdens de lange zeventiende eeuw. In het kader van het Huygens ING project 'Mapping Notes and Nodes in Networks' werden meerdere databases samengevoegd, waaronder de UvA-database Ecartico en de KNIR Hadrianus-database. Ecartico bevat biografische gegevens over leden van de schildersbent, terwijl Hadrianus hun vestigingsdata in Rome te bieden had. De samenvoeging maakte het mogelijk om verblijfpatronen te verkennen en deze te relateren aan de geografische origine van de individuen en hun relatie met de Ro- 


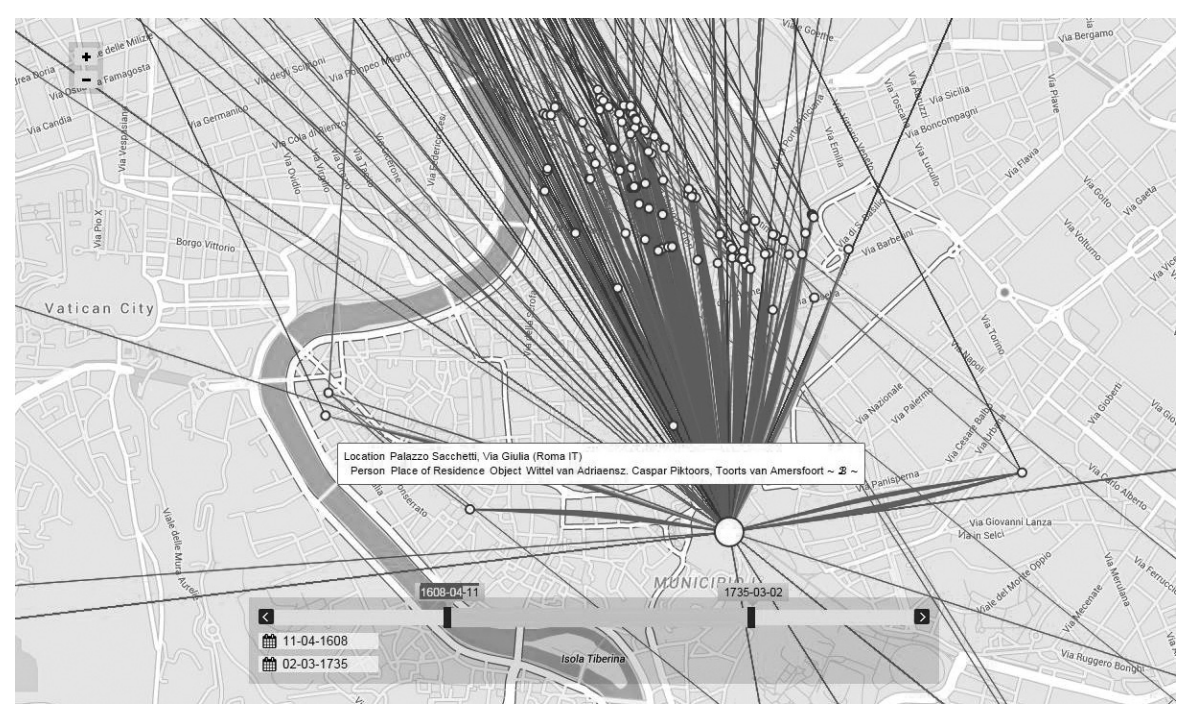

Overzicht van alle woonplaatsen van de Bentvueghels die beschikbaar zijn in de 'Mapping Nodes and Notes'-dataset. Het overzicht beslaat de lange eeuw waarin de Bentvueghel-kunstenaars actief waren in Rome (1620-1720). De (oorspronkelijk blauwe) stippen ten zuidwesten van de andere stippen hebben betrekking op Casper van Wittel.

De visualisatie en het verslag kunnen worden geraadpleegd via http://mnn.nodegoat.net/viewer

meinse gemeenschap. De resulterende geografische visualisaties maakten twee aspecten van deze migratiestroom duidelijk. Om te beginnen wisten de Bentvueghels een cluster op te zetten naast de noordelijke poorten van de stad, waarbinnen ze vervolgens met mensen uit dezelfde stad samen in huis gingen wonen. Ten tweede toont de opvallende casus van Caspar van Wittel (1675-1736) dat deze tijdelijke verblijfslocatie ook als zodanig werd gezien. Ondanks dat hij lid was van de Bentvueghels, woonde van Wittel ver ten zuidoosten van zijn collega's, op een plaats waar hij zich met de locals kon mengen. Dit afwijkende verblijfspatroon kon verklaard worden door terug te gaan naar zijn biografische gegevens: Van Wittel wist een succesvolle carrière op te bouwen als schilder voor het Romeinse patriciaat, en was er dus gebaat bij zich te midden van deze groep te vestigen. Dit voorbeeld laat zien dat onze interessege- bieden en onze bronnen in essentie hetzelfde blijven binnen digitaal onderzoek; het zijn alleen de methodologie en de thematische scope die een nieuwe gestalte krijgen. Dezelfde alfa-doelen, nieuwe behulpzame middelen. Dankzij digitale methodes kunnen we onze bestaande kennis uitdagen en uitbreiden, onverwachte verbanden onthullen, en beter recht doen aan de grensoverschrijdende levens van de mensen en objecten die we bestuderen.

De digitale aanpak dwingt ons om buiten onze comfort zone te komen, en dat kan nooit kwaad. Elke generatie cultuurwetenschappers heeft een turn meegemaakt met als doel de filosofische grondslagen van het vak ter discussie te stellen. Het resultaat daarvan was niet dat voorafgaande perspectieven volkomen uit de academische wereld verdwenen. De vrees daarvoor is dus ook onterecht. Zo kan de digital turn ook tot nieuwe inzichten leiden in combinatie met de bestaande in- 
valshoeken. Netwerkanalyses, het in kaart brengen van archeologische opgravingen, het typeren van schrijftaal of van kunstobjecten, om maar een paar voorbeelden te noemen, kunnen allemaal gecombineerd worden met computationele methodes. Daarmee worden de interesses van de betrokken onderzoekers niet noodzakelijk getroffen - het is vanuit hun vakgegenereerde vraagstukken dat digitale methodes van dienst kunnen zijn. De digitale dimensie respecteert derhalve het vak wanneer zij goed begrepen wordt, en tegelijkertijd confronteren digital humanities de geesteswetenschapper met de voor hem of haar vanzelfsprekende karakteristieken van het eigen materiaal en de onderzoeksmethodologie.

Daarbij vormt digitaal gereedschap een uitstekend middel voor het visualiseren en het delen van onze data. Binnen de academische gemeenschap betekenen deze mogelijkheden meer samenwerking en het vergroten van onze thematische reikwijdte. Daarbuiten is het een ongekende kans om onze uitvindingen met het grote publiek te delen en zodoende maatschappelijke debatten rijker te maken. In dit opzicht is de digital turn wél anders dan andere turns. Nog nooit heeft een nieuwe trend de onderzoekers zó gedwongen om uit hun ivoren torens te komen.

Toen ik acht jaar oud was kregen we thuis Encarta. En iedereen wist dat er geen weg meer terug was. We leven nu in een digitale wereld vol prachtige mogelijkheden voor onze historische gegevens. Computationeel gereedschap gebruikt weliswaar andere principes voor het samenvoegen van data, want deze moeten - in tegenstelling tot onze vaak onzekere kennis - zuiver en compleet zijn. Deze spanning is echter geen onoverbrugbaar obstakel, maar een kans om te reflecteren op ons onderzoeksmateriaal. Voor degenen die deze uitdaging aandurven, staat er veel moois te wachten. Data-integratie biedt ongekende mogelijkheden om nieuwe, onverwachte verbanden te leggen die onze theses in twijfel trekken. Bovendien maken de aangelegde verbindingen het onderzoek rijker in de ruimte en in de tijd, en bieden zij ons de mogelijkheid om samen groter te gaan denken over historische verschijnselen. De resulterende schat aan gegevens kan tevens gedeeld worden met iedereen binnen en buiten de academische sfeer, wat een uitgelezen kans is voor het bevorderen van publieksgeschiedenis. Al deze verschijnselen betekenen niet dat de digital humanities ons vak grondig zullen doen veranderen. Computationeel gereedschap belichaamt een turn die uitstekend samen kan werken met bestaande perspectieven en biedt bovenal nieuwe hulpmiddelen waarvan het zonde zou zijn om die links te laten liggen. Uiteindelijk zijn de digital humanities net als een fraai essay: ze prikkelen de geest, breiden je horizon uit en inspireren de meest fundamentele debatten.

\section{Over de auteur}

Leonor Álvarez Francés MA begon te werken aan een toneeldatabase van de opvoeringen op de Amsterdamsche Schouwburg (1638-1772) tijdens de Onderzoeksmaster Geschiedenis aan de UvA. Dit project, aanvankelijk bedoeld voor haar scriptie, groeide binnen het interfacultaire onderzoeksprogramma CREATE tot de grootschalige online database $\mathrm{ON}$ - 
STAGE. Haar fascinatie voor de digital humanities ontwikkelde zich verder binnen het data-integratie project 'Mapping Notes and Nodes in Networks' (Huygens ING). Tegenwoordig organiseert ze onderwijsprogramma's rondom data-modelling en promoveert ze aan de Universiteit Leiden, waar ze verhalen over Spaanse commandanten in Spaanse en Nederlandse kronieken tijdens de Opstand bestudeert. E-mail:

l.alvarez.frances@hum.leidenuniv.nl

\section{Essayprijs Huizinga Instituut 2016}

In welke opzichten zijn de cultuurwetenschappen gebaat bij digital humanities? Is de aandacht voor big data een voorbijgaande hype of zullen de cultuurwetenschappen door deze nieuwe technologie werkelijk van karakter veranderen? Zullen technologische ontwikkelingen de huidige disciplinaire scheidslijnen in de cultuurwetenschappen veranderen en in hoeverre achten wij die verandering wenselijk? Het Huizinga Instituut schreef in juli 2016 een essaywedstrijd uit over 'nieuwe technologie en de cultuurwetenschappen', waarbij stafleden en promovendi werden uitgenodigd over bovengenoemde vragen te reflecteren.

De geslaagde combinatie van vorm en inhoud, originaliteit en geïnformeerdheid heeft de jury doen besluiten om het essay van Leonor Álvarez Francés te bekronen met de Essayprijs van het Huizinga Instituut 2016. Uit het juryrapport: 'Álvarez Francés [maakt] overtuigend duidelijk dat elke framing van de discussie over digital humanities in termen van voor- en tegenstanders misschien wel vooral gemakzuchtig is en de wetenschap niet verder brengt.'

De jury bestond uit prof. dr. Rens Bod (Universiteit van Amsterdam) en prof. dr. Jan Hein Furnée (Radboud Universiteit Nijmegen) namens de Adviesraad en Milou van Hout MA (Universiteit van Amsterdam) namens de Promovendiraad. De prijsuitreiking vond plaats op 14 december 2016 in Leiden. 